Running head: SOURCE IDENTITY \& EXPERTISE EFFECTS ON PERFORMANCE

\title{
Being One Of Us: Translating Expertise Into Performance Benefits Following Perceived Failure
}

\author{
Olivier Rascle ${ }^{1}$, Maxime Charrier ${ }^{1}$, Nancy Higgins ${ }^{2}$, Tim Rees ${ }^{3}$, Pete Coffee ${ }^{4}$, \\ David Le Foll ${ }^{1}$, and Genevieve Cabagno ${ }^{1}$ \\ ${ }^{1}$ UFRSTAPS, Université Rennes 2, Laboratory VIPS2, EA 4636, France \\ ${ }^{2}$ Department of Psychology, St Thomas University, Fredericton, Canada E3B 5G3 \\ ${ }^{3}$ Department of Sport \& Physical Activity, Bournemouth University, Poole, UK \\ ${ }^{4}$ School of Sport, University of Stirling, Scotland, UK
}

\section{Corresponding Author:}

Dr. Olivier Rascle, UFRSTAPS, Université Rennes 2, France olivier.rascle@ univ-rennes2.fr

\section{Acknowledgements}

We would like to thank Dr. Marvin Claybourn for his helpful comments on an earlier version of the manuscript.

This research was supported in part by a grant from the Ministère des Affaires étrangères et européennes, Programme Hubert Curien Alliance (22755 TJ) and the "Alliance: Franco-British Partnership Programme 2010" of The British Council (Project Number 10021), and by a Carnegie Research Grant awarded to the last author from The Carnegie Trust for the Universities of Scotland.

Word count (exc. figures/tables): 9487 (without the abstract) 
1 Being One of Us: Translating Expertise Into Performance Benefits Following Perceived Failure After failure, managers and educators (teachers, coaches, therapists, parents) often must

3 deliver feedback that is aimed at improving performance; thus, it is important to understand

4 factors that foster (or not) a renewed desire to persist despite setbacks. Extensive attribution

5 research demonstrates a direct relationship between causal attributions and performance (e.g.,

6 Dweck \& Leggett, 1988; Hong, Chiu, Dweck, Lin, \& Wan, 1999; Mueller \& Dweck, 1998).

7 Attributions - the specific causes used to explain outcomes-elicit specific emotions and

8 expectancies about the future, which influence subsequent behaviours (Weiner, 1985; cf.

9 Rudolph, Roesch, Greitemeyer, \& Weiner, 2004). Dysfunctional attributions for failure (i.e.,

10 focusing on relatively fixed, unchanging features of oneself, such as [low] ability) typically

11 result in giving up; in contrast, functional attributions for failure (i.e., focusing on relatively

12 malleable features of oneself, such as [poor] strategy) typically result in continued attempts to

13 improve (Molden \& Dweck, 2006). Leading individuals to form functional attributions following

14 failure (i.e., that the cause of their performance was within their control—controllable—and

15 something they could change-unstable) has positive effects on performance in academic

16 (Haynes, Perry, Stupnisky, \& Daniels, 2010) and sport domains (Coffee, Rees, \& Haslam, 2009).

17 Research examining features of feedback sources (e.g., ingroup/outgroup membership,

18 expertise), and their communications (e.g., argument quality), began to expand rapidly in the

19 early 1970's with the work of Tajfel (e.g., Tajfel \& Turner, 1979, 1986). Since then, social

20 identity research has been extensive (Marx \& Goff, 2005; Smith \& Hogg, 2008; Steele, 1997). In

21 general, the effectiveness of feedback in improving performance depends upon the expertise of

22 the feedback source, with many studies finding that expert sources are more influential than non-

23 experts (Petty \& Wegener, 1998; Smith \& Hogg, 2008; Tobin \& Raymundo, 2009). Yet, despite 
1 the link between high source expertise and the effectiveness of feedback, and while success

2 stories are common, there are many examples of otherwise successful coaches or managers who

3 failed to enhance players' or employees' performance when they integrate a new team or

4 company. Thus, questions remain about what other factors make source expertise effective in

5 enhancing performance after failure.

6 A well-documented finding in social identity research is that feedback from outgroup

7 sources is less effective than feedback from ingroup sources, regardless of the expertise,

8 experience, or credibility of the source (e.g., Greenaway, Wright, Willingham, Reynolds, \&

9 Haslam, 2015; Morton, Wright, Peters, Reynolds, \& Haslam, 2012; Petty \& Wegener, 1998).

10 Similarly, feedback from outgroup sources is less effective than feedback from ingroup sources

11 regardless of the quality of the argument (e.g., Esposo, Hornsey, \& Spoor 2013). A good deal of

12 social identity research has examined effects due to ingroup/outgroup membership. "Ingroup"

13 refers to a group an individual identifies with and feels positively about. By contrast, "Outgroup"

14 refers to a group with which an individual does not identify. When a person identifies with a

15 group, they perceive themselves and group members as different from other groups, accentuating

16 ingroup member effects. For example, there could be an ingroup-outgroup distinction between

17 fans of different sports teams or between students of different schools/universities. Phenomena

18 addressed as a function of the ingroup-outgroup distinction include, for example, the intergroup

19 sensitivity effect (ISE; Hornsey, Oppes, \& Svensson, 2002), which indicates people are more

20 resistant to criticisms of their group (negative feedback) when those criticisms are made by an

21 outgroup rather than an ingroup member, irrespective of whether the criticism is objectively

22 well-justified or well-argued (Esposo, Hornsey, \& Spoor 2013). It appears that source expertise,

23 or other source or argument features, typically are not sufficient to offset outgroup membership, 
1 and the effectiveness of ingroup sources as communicators is a function of the greater attention

2 paid to ingroup members and thus to their features (such as expertise), or features of their

3 feedback (such as quality) (e.g., Hornsey \& Imani 2004).

4 Additional confirmation of the finding that source expertise is not sufficient to offset

5 outgroup membership comes from research on "stereotype threat" (e.g., Marx \& Roman, 2002;

6 Tajfel \& Turner, 1979). For example, because mathematics is seen as a masculine domain,

7 women who endorse and are threatened by this stereotype tend to have poorer performance on

8 standardized math tests compared to men (Steele, 1997). While women's and men's performance

9 on the math tests is comparable if administered by a high expert female teacher, women show

10 performance decrements if the test is administered by a high expert male teacher (Marx \&

11 Roman, 2002). In stereotype threat research, the saliency of a social identity feature that raises a

12 negative stereotype about performance (e.g., gender (male/female) for math ability, or race (race:

13 black or white) for verbal ability) has been shown to affect performance only of ingroup

14 members; the expertise of an outgroup tester did not offset the effect of group identity on

15 performance (Marx \& Goff, 2005; Marx \& Roman, 2002; Steele \& Aronson, 1995; cf.

16 Chalabaev, Sarrazin, Fontayne, Boiché, \& Clément-Guillotin, 2013).

17 Thus, source identity (ingroup/outgroup) and expertise appear to play an important role in

18 feedback effectiveness; while expertise of an outgroup source appears to be irrelevant, the

19 expertise of an ingroup source is quite relevant. Given the vast literature about the effectiveness

20 of functional attributional feedback on performance, it is surprising that very little is known

21 about whether social identity variables moderate the effects of functional attributional feedback

22 on performance, particularly in performance relevant settings (Coffee, 2010; Rabinovich,

23 Morton, Crook, \& Travers, 2012). The practical advantages of knowing what fosters the desire to 
1 persist despite setbacks will be helpful to coaches, educators, and leaders when delivering

2 feedback aimed at improving performance. In addition, knowing whether a shared common

3 identity is beneficial in the transfer of expertise might be more important than acquiring more

4 expertise or reconfiguring how to deliver that expertise. Some research is beginning to address

5 this gap in the literature. For example, in a recent study, functional attributional feedback

6 allowed participants to recover from repeated failures in a dart throwing task only when the

7 feedback was delivered by an ingroup member (Rees et al., 2013). Encouraging feedback

8 delivered by an outgroup member (who attended a prestigious sport university) did not affect

9 performance, which suggests an ingroup favoritism effect (Rees et al., 2013; Tajfel \& Turner,

10 1986). In the Rees et al. (2013) study, source expertise was not manipulated, but was suggested

11 by the prestige of the source's university.

12 Given that the greater attention paid to the expertise of ingroup sources of feedback has

13 not been investigated in performance relevant settings, we designed two field experiments to

14 assess the influence of source identity (ingroup/outgroup) and source expertise (low/high) on the

15 effectiveness of encouraging feedback on performance following failure. To our knowledge, the

16 effect of encouraging feedback about failure from low or high expert ingroup or outgroup

17 sources on actual performance in a field setting has not been investigated. Based on previous

18 findings reviewed here, we expected that, following failure in a sports task in a field setting,

19 performance improvement would follow functional feedback (i) from a high expert source

20 (compared to a low expert source), (ii) from an ingroup source (compared to an outgroup

21 source), and (iii) there would be a potential interactive effect, with best performance post-failure

22 achieved by those receiving functional feedback from an ingroup source with high expertise,

23 compared to other conditions. 


\section{Experiment 1}

2 Method

$3 \quad$ Participants

4 One hundred twenty nine students (69 male, 60 female, mean age $=12.5, S D=.90)$ from

5 a school located in northwest France provided informed consent to participate in the study.

6 Power analysis using G*Power 3.1 (Faul, Erdfelder, Lang, \& Buchner, 2007; Faul, Buchner,

7 Erdfelder, \& Lang, 2014) indicated that based on an effect size $\left(\eta_{\mathrm{p}}{ }^{2}=0.16\right)$ from task

8 performance measures in previous research (Rascle, Le Foll, Charrier, Higgins, Rees, \& Coffee;

9 2015; Rascle, Le Foll, \& Higgins, 2008), twenty-four participants per group were considered

10 sufficient to achieve a power of 0.9 in a $F$-test, at an $\alpha=0.05$. Given the practical limitations that

11 often accompany field research in schools, we therefore aimed for a minimum sample size of 120

12 students for the field experiment so that the per condition cell size would be approximately 30

13 participants.

14 Design

15 Participants were randomly assigned to one of four conditions in a 2 Source (ingroup,

16 outgroup) $\times 2$ Source Expertise (low, high) design, as follows: Ingroup source with Low

17 Expertise (30 participants), Ingroup source with High Expertise (34 participants), Outgroup

18 source with Low Expertise (34 participants), Outgroup source with High Expertise (31

19 participants).

20 Measure

21 In the throwing task, individuals were asked to throw six soft, adhesive balls, one at a

22 time, as close as possible to the centre of a target. The sticky target had a radius of 18

23 centimetres and was attached to a wall 2.5 metres in front of the participant. The spot where each 
1 participant stood for the throwing task was drawn on the floor. Each participant was informed (i)

2 the objective of the task was to score as low as possible (i.e., get each ball as close as possible to

3 the target), (ii) that their performance would be calculated as the sum of the six distances

4 between the place where the ball stuck and the centre of the target, and (iii) that a total score of 0

5 was the best performance they could achieve. The distance for each throw was calculated with a

6 measuring tape marked in centimetres from the centre of the target (marked by a black dot) to the

7 centre of the ball (where it came to rest) on each trial. Participants' scores summed over six trials

8 ranged from 39 to 160 centimetres, with higher scores indicating poorer performance.

9 Because the study was examining the effects of functional feedback after failure, this

10 difficult throwing task was chosen (not a standard task that students would be familiar with) to

11 ensure that most students would not do well and would perceive their Trial 1 performance as

12 poor (as failure). We wanted to ensure that participants felt as though they had failed before the

13 attributional feedback was delivered, and thus we excluded (from the statistical analyses) those

14 participants who felt their performance on the task was a success. Although a person's

15 perception of their performance failure is often consistent with the actual outcome, it sometimes

16 happens that people whose performance is objectively poor still feel as though their performance

17 was a success (Le Foll, Rascle, \& Higgins, 2008).

18 After three practice throws, participants individually completed a first trial of six throws

19 and were asked to evaluate their Performance 1 score as "rather like a success" or "rather like a

20 failure". Of the 129 participants, 122 perceived their score "rather like a failure" and were

21 included in subsequent statistical analyses. The final sample breakdown for the statistical

22 analyses was as follows: Ingroup source with Low Expertise (28 participants), Ingroup source

23 with High Expertise (33 participants), Outgroup source with Low Expertise (32 participants), 
1 Outgroup source with High Expertise (29 participants). There were no significant mean age

2 differences between groups.

\section{$3 \quad$ Procedure}

$4 \quad$ The experiment was introduced by a Physical Education (PE) teacher during a PE lesson

5 as a test of precision throwing ability being undertaken in several schools. The testing consisted

6 of the throwing task described above and took place in a room near the gymnasium during a PE

7 class, so that classmates were not able to observe the participant during the task. Students (18-24

8 per class) were tested individually, with testing taking approximately seven minutes per student.

9 The students entered the testing room one at a time, and then returned to their PE class.

10 After completing the first set of six throws, each participant was then provided with

11 standardized functional feedback (e.g., Rees et al., 2013) informing them the cause of their

12 performance was within their control (controllable) and something they could change (unstable).

13 The feedback was stated as follows: "The causes of your performance in this task seem to reflect

14 mostly personally controllable and unstable factors, such as your concentration, your effort, or

15 the strategy you used to try to succeed in the task. As you know, you have personal control over

16 the effort you put into the task or the strategy you use, and the intensity of your effort or

17 concentration might change over time." For all participants, we gave examples of functional

18 attributions such as effort (e.g., "maybe my throws weren't strong enough") and strategy (e.g.,

19 "maybe my aim was too high"). In addition, to facilitate retention of the feedback, a whiteboard

20 including keywords in the feedback (cause of your performance: controllable and unstable-

21 effort, strategy) was posted beside the target during the Trial 2 testing session. Feedback was

22 provided by either an ingroup or outgroup source. The Ingroup source was the pupils' usual

23 teacher (one male and one female). The Outgroup source, a male PE teacher the pupils did not 
1 know from another school, was introduced to pupils during a PE lesson as a PE teacher who was

2 involved in conducting a test of precision ability that was being undertaken in several schools in

3 the area. After providing the feedback on Performance 1, the source informed the pupils of their

4 expertise (high versus low expertise) in this type of task. After the feedback on Performance 1

5 was delivered and source expertise revealed, participants individually completed a second ball-

6 throwing trial of six tries (Trial 2 performance score).

7 The choice to indicate the expertise of the source after delivering the attributional

8 feedback was made because some research indicates that the order of presentation of expertise

9 (before or after delivering a communication) could impact participants' attitudes. For example,

10 Tormala, Briñol, and Petty (2006) observed that when people have primarily negative thoughts

11 in response to a message (e.g., because it contains weak arguments), high source credibility leads

12 to less favorable attitudes than does low source credibility. Similarly, Mackie, Gastardo-Conaco,

13 and Skelly (1992) observed that ingroup messages were more likely to receive content-focused

14 processing (as indicated by larger processing times) when position advocacy followed rather than

15 preceded message presentation. Although we did not provide different quality arguments in our

16 study, we expected that some of our participants might perceive the encouraging attributional

17 feedback as "weak", and thus we decided to deliver the expertise of the source after, rather than

18 before, the feedback.

19 Data analysis

20 All data are reported as means and standard deviations (SD). Prior to the analysis, the

21 Shapiro-Wilk test and Box's M test were employed to test assumptions of normality and

22 homogeneity of the variance-covariance matrices, respectively. Both assumptions were met. A

23 mixed $2 \times 2 \times 2$ ANOVA with the source (ingroup, outgroup) and source expertise (low, high) as 
1 between-subjects factors, and trial (trial 1, trial 2) as the within-subjects factor was used to

2 examine differences in performance between the conditions prior to (trial 1) and after (trial 2) the

3 delivery of the attributional feedback.

4 In addition, a two-way between-subjects $2 \times 2$ ANOVA was used to examine differences

5 in perceived expertise between the source (ingroup, outgroup) and source expertise (low, high)

6 conditions to explore the success of the experimental manipulations.

$7 \quad$ Measures of effect size (partial eta-squared $\left(\eta_{\mathrm{p}}{ }^{2}\right)$ ) for univariate analyses, and Cohen's $d$

8 for $t$-tests are reported for all significant effects. Significance was set at 0.05 (two-tailed) for all

9 analyses, unless otherwise stated. Based on criteria outlined by Bakeman (2005), $\eta_{\mathrm{p}}{ }^{2}$ values of

$10.02, .13$, and .26 , and Cohen's $d$ values of $.20, .50$, and .80 were taken as corresponding to small,

11 medium, and large effect sizes, respectively. Data analysis was conducted using the Statistical

12 Package for the Social Sciences, version 24 (SPSS Inc., Chicago, IL, USA).

\section{Results}

\section{Manipulation checks}

15 Source. The source manipulation was not formally checked using a measure of perceived

16 ingroup/outgroup. However, the operationalization of Source (known PE teacher versus

17 unknown PE teacher) was considered strong enough for the purposes of the field study, as pupils

18 typically only attend one school and teachers typically do not teach at more than one school at a

19 time (both of which were the case in the present study).

20 Source expertise. To check the perception of source expertise, pupils were asked to

21 anonymously answer one question, "Do you think this teacher is an expert on this task?", with

22 responses on a 6-point scale ranging from 1 ("not at all") to 6 ("completely"). The source

23 expertise manipulation check question was asked after Trial 2 was completed. 
The analysis revealed no main effect of Source $\left(F(1,118)=3.64, p=.059, \eta_{\mathrm{p}}{ }^{2}=.030\right)$, a

2 main effect of Source Expertise $\left(F(1,118)=17.55, p=.000, \eta_{\mathrm{p}}{ }^{2}=.130\right)$, and no Source $\times$

3 Source Expertise interaction $\left(F(1,118)=1.09, p=.29, \eta_{\mathrm{p}}^{2}=.009\right)$. There was no difference in

4 the perceived expertise of the outgroup $(M=4.65, S D=1.43)$ and ingroup $(M=4.16, S D=1.36)$

5 sources, $\mathrm{CI}=[-.92 ; .01])$. The high expert source $(M=4.93, S D=1.11)$ was viewed as having

6 greater expertise in the task than the low expert source $(M=3.86, S D=1.47), C I=[-1.56 ;-.64]$,

7 indicating the success of the source expertise manipulation. The expertise manipulation was

8 effective in the ingroup $\left(F(1,59)=4.85, p=.032, \eta_{\mathrm{p}}{ }^{2}=.009, \mathrm{CI}=[-1.42 ;-.06]\right)$ and outgroup

9 conditions $\left(F(1,59)=13.96, p=.000, \eta_{\mathrm{p}}^{2}=.19, \mathrm{CI}=[-1.91 ;-.58]\right)$.

\section{Performance}

The analysis revealed a main effect for Trial $\left(F(1,118)=11.29, p=.001, \eta_{\mathrm{p}}{ }^{2}=.087, \mathrm{CI}=\right.$

$12[3.50 ; 13.57])$, indicating that, overall, performance scores improved from Trial $1(M=104.54$,

$13 S D=22.94)$ to Trial $2(M=95.63, S D=26.03)$. Paired sample $t$-tests of Trial means within each

14 group revealed that performance improved from Trial 1 to Trial 2 only in the Ingroup High

15 Expertise condition, $\left(M_{T 1}=105.36[S D=20.93], M_{T 2}=85.67[S D=21.53]\right), t(32)=4.32, d=$

$16.75, p=.000$. There was no significant performance improvement from Trial 1 to Trial 2 in any

17 of the other conditions, as follows: Ingroup Low Expertise condition, $\left(M_{T 1}=107.60[S D=\right.$

$\left.1822.62], M_{T 2}=106.00[S D=24.65]\right), t(27)=0.27, d=.05, p=.786$; Outgroup High Expertise

19 condition, $\left(M_{T 1}=103.93[S D=22.27], M_{T 2}=97.03[S D=30.98]\right), t(28)=1.38, d=.25, p=$

20 .176; and Outgroup Low Expertise condition, $\left(M_{T 1}=101.56[S D=26.26], M_{T 2}=95.59[S D=\right.$ $2123.79]), t(31)=1.19, d=.21, p=.241$.

In terms of between-subjects effects in the $2 \times 2 \times 2$ repeated measures ANOVA, there

23 was no main effect of Source $\left(F(1,118)=.206, p=.651, \eta_{\mathrm{p}}{ }^{2}=.002\right)$, no main effect of Source 
1 Expertise $\left(F(1,118)=1.70, p=.194, \eta_{\mathrm{p}}{ }^{2}=.014\right)$, and no Source $\times$ Source Expertise interaction

$2\left(F(1,118)=3.37, p=.069, \eta_{\mathrm{p}}^{2}=.028\right)$. In terms of interactions with the Trial variable, the Trial

$3 \times$ Source interaction was non-significant, $\left(F(1,118)=.689, p=.408, \eta_{\mathrm{p}}{ }^{2}=.006\right)$, as was the

4 Trial $\times$ Source Expertise interaction, $\left(F(1,118)=3.49, p=.064, \eta_{\mathrm{p}}{ }^{2}=.029\right)$, and the Trial $\times$

5 Source $\times$ Source Expertise interaction, $\left(F(1,118)=2.84, p=.094, \eta_{\mathrm{p}}^{2}=.024\right)$.

Although the hypothesized three-way interaction of Trial $\times$ Source $\times$ Source Expertise

7 interaction (see Figure 1) did not reach significance $(p=.094)$, we proceeded to explore Trial 1

8 and Trial 2 scores separately in 2 Source (ingroup, outgroup) $\times 2$ Source Expertise (low, high)

9 ANOVAs. For the Trial 1 performance scores, the analysis revealed no main effect of Source

$10\left(F(1,118)=.793, p=.375, \eta_{\mathrm{p}}^{2}=.007\right)$, no main effect of Source Expertise $(F(1,118)=.000, p=$ $\left.11.988, \eta_{\mathrm{p}}{ }^{2}=.000\right)$, and no Source $\times$ Source Expertise interaction $\left(F(1,118)=.382, p=.584, \eta_{\mathrm{p}}{ }^{2}=\right.$

12 .003). For the Trial 2 performance scores, the analysis revealed no main effect of Source, $(F(1$,

$\left.13118)=.011, p=.917, \eta_{\mathrm{p}}{ }^{2}=.000\right)$. However, there was a main effect of Source Expertise, $(F(1$,

$\left.14118)=4.22, p=.042, \eta_{\mathrm{p}}{ }^{2}=.035, \mathrm{CI}=[.34 ; 18.54]\right)$, indicating that Trial 2 performance scores

15 were better in the high expertise condition $(M=91.35, S D=26.77)$ compared to the low

16 expertise condition $(M=100.79, S D=24.55)$, and there was also a significant interaction of

17 Source $\times$ Source Expertise, $F(1,118)=5.61, p=.019, \eta_{\mathrm{p}}{ }^{2}=0.045$. Simple effects analysis of the

18 interaction showed there was a main effect for source expertise only in the ingroup condition,

$19\left(F(1,59)=11.82, p=.001, \eta_{\mathrm{p}}^{2}=.167, \mathrm{CI}=[8.50 ; 32.16]\right)$, with better Trial 2 performance in the

20 high expertise condition $(M=85.67, S D=21.53)$ than in the low expertise condition $(M=$

21 106.00, $S D=24.65)$. There was no main effect for source expertise in the outgroup condition,

$22\left(F(1,59)=.042, p=.838, \eta_{\mathrm{p}}{ }^{2}=.001, \mathrm{CI}=[-15.52 ; 12.63]\right)$, indicating no difference in Trial 2 
1 performance in the high $(M=97.03, S D=30.98)$ and low $(M=95.59, S D=23.79)$ expertise

2 conditions.

3 Discussion

4 Thus, source expertise positively influenced Trial 2 performance scores, with high source 5 expertise only translating into better performance through functional feedback when it was

6 provided by a member of one's ingroup. In other words, following failure, a salient social

7 identity factor appears to be a prerequisite for source expertise to benefit performance.

8 Although these results were promising, one limitation of Experiment 1 was the non-

9 significant hypothesized three-way interaction of Source $\times$ Source Expertise $\times$ Trial; ideally, the

10 ingroup expertise effect should have revealed itself in a clearly significant three-way interaction,

11 but in the current dataset the $p$-value was .094 for the interaction. Because this value was

12 approaching significance, and because we had predicted the interaction, we explored the

13 interaction to examine whether the ingroup expertise effect was in the direction we expected, and

14 the results confirmed our prediction. A second limitation of Experiment 1 was the possibility that

15 the ingroup expertise effect was due to source familiarity, or a "double-dose" of expertise effect,

16 in which pupils were told that someone (i) who teaches them regularly is (ii) an expert in the

17 performance task. Given this possible alternative explanation for the Experiment 1 interaction

18 effect on Trial 2 performance scores, we planned a second experiment to address this potential

19 confound.

\section{Experiment 2}

21 Experiment 2 was designed to examine the hypothesized three-way interaction of Source

$22 \times$ Source Expertise $\times$ Trial, with changes to rule out the possibility of a "familiarity/double dose

23 of expertise" confound, described below. A second objective of Experiment 2 was to examine a 
1 possible cognitive explanation for the influence of source characteristics on performance. With

2 high source expertise, encouraging feedback may be taken seriously and consequently increase

3 success expectations, but with a low expert source, encouraging feedback may be taken less

$4 \quad$ seriously and be accompanied by doubts about future success. Since functional feedback

5 generally leads to an improvement of success expectations following failure (Rascle et al., 2008),

6 we hypothesized that success expectations would mediate the influence of source characteristics

7 on performance.

8 Method

9 Participants

10 One hundred twenty French undergraduate students (81 male, 39 female; mean age $=$

$1119.3, S D=.80)$ from a university in northwest France volunteered to participate in the study after

12 providing informed consent. The participants were all first year students and were drawn from

13 the same sport psychology course. We again aimed for a minimum sample size of 120 students

14 for the field experiment to ensure the per condition cell size would be approximately 30

15 participants.

16 Design

17 Participants were randomly assigned to one of four conditions in a 2 Source (ingroup, 18 outgroup) $\times 2$ Source Expertise (low, high) design, as follows: Ingroup source with Low

19 Expertise (33 participants), Ingroup source with High Expertise (31 participants), Outgroup

20 source with Low Expertise (29 participants), Outgroup source with High Expertise (27

21 participants). 


\section{Measures}

Performance task. The performance task consisted of counting the number of images of a specific sport (e.g., badminton) among 80 scrolling images of multiple sports (badminton, volleyball, gymnastics, swimming, skiing, tennis). Each participant, tested separately, was seated at a desk and on a screen facing the participant, two meters away, the 80 scrolling images were projected using Powerpoint. Each image was on the screen for 0.2 seconds and thus the entire image presentation lasted 16 seconds. At the end of the projection, the participant had 10 seconds to indicate his/her answer on a paper sheet provided for this purpose. The number of badminton images in the first trial was 20 , and in the second trial was 16 . Performance was measured as the difference between the number of badminton images a participant reported and the actual number of badminton images. To ensure performance in the first trial lead to failure, 2 points per error were subtracted from the possible best score of 20, and participants were informed of their score (but were unaware of the penalty points). For example, if a student missed 8 of the 20 badminton images, the student would be told that his or her score was 4/20 (20\%). This task was chosen (not a standard task students would be familiar with) to allow us to use false score feedback in which participants would perceive their Trial 1 performance as poor (as a failure). We wanted to ensure that participants felt as though they had failed before the attributional feedback was delivered and thus excluded (from statistical analyses) participants who felt their performance on the task was a success.

Immediately after being informed of their performance on the first trial, participants completed a measure of their perceived performance. Ten participants perceived their

22 performance as "rather like a success", and the Trial 1 performance of four participants was more than three standard deviations away from the average. These 14 participants were excluded from 
1 subsequent statistical analyses, leaving a final sample of 106 participants. The final sample

2 breakdown for the statistical analyses was as follows: Ingroup source with Low Expertise (30

3 participants), Ingroup source with High Expertise (27 participants), Outgroup source with Low

4 Expertise (25 participants), Outgroup source with High Expertise (24 participants). There were

5 no significant mean age differences between groups.

6 We used the actual numbers of errors in each trial as the dependent measure, but because

7 the number of target images was 20 in Trial 1 and 16 in Trial 2, performance scores were

8 calculated as percent error to ensure comparability of Trial 1 and Trial 2 performance scores for

9 the analyses. The choice to use error scores was made so that for the two studies, lower scores

10 indicate better performance, rather than better in one case (Experiment 1) and worse in the other

11 (Experiment 2, had we used percentage of correct answers).

12 Success expectations. As in previous studies (Le Foll et al., 2008; Rascle et al., 2015;

13 Rascle et al., 2008), success expectations were evaluated prior to Trial 2 using the following

14 question: "Do you think you can improve on the next trial?", and participants responded to the

15 question by marking a line across a 10 centimeter line between two extremes anchored at either

16 end by "absolutely sure of, no" to "absolutely sure of, yes". The success expectations score was

17 calculated by taking a participant's mark on the $10 \mathrm{~cm}$ line and converting it to a percentage

18 score, with $0 \mathrm{~cm}$ equivalent to 0 percent and $10 \mathrm{~cm}$ equivalent to 100 percent; thus, higher scores

19 indicated a higher success expectation. The success expectations question was asked after Trial 1

20 was completed and the feedback delivered.

\section{$21 \quad$ Procedure}

22 The design and procedure were the same as Experiment 1 with the following additions:

23 (a) the same individual delivered the feedback in all the conditions; (b) the task was different 
1 from the throwing task used in Experiment 1; and (c) a success expectations measure was

2 completed after receiving the attributional feedback and information about the source's expertise

3 was revealed, and before students completed Trial 2.

4 In Experiment 2, to rule out the possibility of a familiarity/double dose of expertise

5 confound, we used the same course instructor in the ingroup and outgroup conditions and

6 ensured that the university students had no contact (outgroup) or almost no contact (ingroup)

7 with the course instructor prior to the experiment. In order to ensure this, Experiment 2 was run

8 very early in an academic term (in the first two weeks of the term). Students in the ingroup

9 condition met with the course instructor for three hours in the first class of the term (in which the

10 experiment was run), and they had not yet received any evaluation from the instructor. Thus, the

11 ingroup students could recognize their instructor, knew the instructor was from their university,

12 but had no individual contact with the instructor (only group contact). Students in the outgroup

13 condition had not yet met their course instructor, and when the experiment was run in their first

14 class (which was in the second week of the term), the instructor introduced himself as a visiting

15 instructor from a rival university who was there to conduct a performance test that was being

16 undertaken in several universities. The information about being from a "rival" university was

17 meant to highlight the outgroup status of the instructor (for the purpose of the experiment). Only

18 after the experiment (during debriefing) did students in the outgroup condition find out the

19 instructor was in fact an instructor at their own university (but not an instructor for any of their

20 courses).

21 The testing consisted of the image-counting task described above and took place in a

22 room near the participants' classroom, so that classmates were unable to observe the participant

23 during the task. In the instructions for the image-counting task, participants were told it was a 
1 "visual acuity task" with the ostensible reason being that in most sports, visual acuity is an

2 essential quality (i.e., being able to process visual information very quickly). After completing

3 the first image-counting trial and receiving their score (Trial 1 performance score), each

4 participant was then provided with standardized functional feedback informing them the cause of

5 their performance was within their control (controllable) and something they could change

6 (unstable) as in Experiment 1. After providing the feedback on Performance 1, the source

7 informed the students of their expertise (high versus low expertise) in this type of task. After the

8 feedback on Performance 1 was delivered and source expertise revealed, all the participants were

9 informed that the correct total number of images in Trial 2 might be different from the correct

10 total in Trial 1 to ensure that participants would not assume that "good performance" was the

11 same in both trials. Participants then individually completed a second image-counting trial (Trial

122 performance score).

\section{Data analysis}

14 The data analysis approach was the same as in Experiment 1, with the following

15 additions: (i) a two-way between-subjects $2 \times 2$ ANOVA used to examine the effect of source

16 characteristics on success expectations in the source (ingroup, outgroup) and source expertise

17 (low, high) conditions, and (ii) linear regression analysis was used to test success expectations as

18 a mediator of the effect of expertise on performance change scores in each of the source

19 (ingroup, outgroup) conditions.

\section{Results}

\section{Manipulation checks}

Source. The source manipulation was checked after performance was measured in Trial

23 2, using two questions that each required a yes/no answer, as follows: (i) "do you know this 
1 instructor?", and (ii) "is this instructor a member of your university?". Asking about the source

2 afterward ensured behaviour in the experiment was not affected by making students suspicious

3 about the purpose of the experiment. All students correctly identified the instructor as an ingroup

4 or outgroup member. Thus the operationalization of source in Experiment 2 was confirmed. This

5 operationalization of ingroup/outgroup membership is very similar to Rabinovich et al. (2012),

6 who had students read an article written by a fellow student of their university (ingroup) or a

7 student of another university (outgroup), and then identify the affiliation of the source.

8 Source expertise. The source expertise manipulation check question was asked after

9 Trial 2 was completed. The scale to measure perceived source expertise was similar to the

10 success expectations scale, with a 10 centimeter line between two extremes anchored at either

11 end by "not at all" to "completely". The perceived expertise score was calculated by taking a

12 participant's mark on the $10 \mathrm{~cm}$ line and converting it to a percentage score, with $0 \mathrm{~cm}$

13 equivalent to 0 percent and $10 \mathrm{~cm}$ equivalent to 100 percent; thus, higher scores indicated higher 14 perceived expertise.

15 The analysis revealed a main effect of Source $\left(F(1,102)=11.03, p=.001, \eta_{\mathrm{p}}{ }^{2}=.098\right)$, a

16 main effect of Source Expertise $\left(F(1,102)=8.20, p=.005, \eta_{\mathrm{p}}{ }^{2}=.074\right)$, and no Source $\times$ Source

17 Expertise interaction $\left(F(1,102)=.001, p=.97, \eta_{\mathrm{p}}{ }^{2}=.000\right)$. The ingroup source $(M=69.15, S D$

$18=21.41)$ was perceived as higher in expertise than the outgroup source $(M=55.97, S D=21.07)$,

$19 \mathrm{CI}=[5.38 ; 21.35])$. The high expert source $(M=68.54, S D=19.96)$ was perceived as more

20 expert than the low expert source $(M=57.02, S D=21.22), \mathrm{CI}=[-19.51 ;-3.54]$, indicating the

21 success of source expertise manipulation. The expertise manipulation was effective in the

22 ingroup $\left(F(1,55)=4.47, p=.039, \eta_{\mathrm{p}}{ }^{2}=.075, \mathrm{CI}=[-22.71 ;-.615]\right)$ and outgroup conditions

$23\left(F(1,47)=3.78, p=.029\right.$ (one-tailed), $\left.\eta_{\mathrm{p}}^{2}=.070, \mathrm{CI}=[-21.21 ;-1.56]\right)$. 


\section{Performance}

Trial 1 and 2 performance scores were analyzed in a 2 Source (ingroup, outgroup) $\times 2$

3 Source Expertise (low, high) $\times 2$ Trial (trial 1 (pre-feedback), trial 2 (post-feedback)) ANOVA,

4 with repeated measures on the last factor. The analysis revealed a main effect for Trial $(F(1,102)$

$\left.5=211.30, p=.000, \eta_{\mathrm{p}}{ }^{2}=.674, \mathrm{CI}=[20.35 ; 26.78]\right)$, indicating that, overall, performance scores

6 improved from Trial $1(M=44.39, S D=9.24)$ to Trial $2(M=20.97, S D=15.47)$. Paired sample

$7 t$-tests of Trial means within each group revealed that performance improved from Trial 1 to

8 Trial 2 in each of the groups, with the largest improvement in the Ingroup High Expertise

9 condition, $\left(M_{T 1}=44.25[S D=8.62], M_{T 2}=13.19[S D=10.00]\right), t(26)=14.01, d=2.69, p=$

10.000 . Significant performance improvement from Trial 1 to Trial 2 in the other conditions was as

11 follows: Ingroup Low Expertise condition, $\left(M_{T 1}=38.33[S D=9.76], M_{T 2}=21.04[S D=17.71]\right)$,

$12 t(29)=4.77, d=.87, p=.000 ;$ Outgroup High Expertise condition, $\left(M_{T 1}=46.25[S D=10.24]\right.$,

$\left.13 M_{T 2}=26.82[S D=16.53]\right), t(23)=4.73, d=.96, p=.000 ;$ and Outgroup Low Expertise

14 condition, $\left(M_{T 1}=49.00[S D=7.21], M_{T 2}=22.50[S D=15.41]\right), t(24)=10.16, d=2.03, p=$ $15 \quad .000$.

16 In terms of between-subjects effects in the $2 \times 2 \times 2$ repeated measures ANOVA, there

17 was a main effect of Source $\left(F(1,102)=14.38, p=.000, \eta_{\mathrm{p}}{ }^{2}=.124, \mathrm{CI}=[-10.56 ;-3.30]\right)$,

18 indicating that, overall, performance scores were better in the ingroup $(M=29.23, S D=12.31)$

19 than the outgroup condition $(M=36.13, S D=12.40)$. There was no main effect of Source

20 Expertise $\left(F(1,102)=.002, p=.962, \eta_{\mathrm{p}}{ }^{2}=.000\right)$, and no Source $\times$ Source Expertise interaction

$21\left(F(1,102)=.228, p=.634, \eta_{\mathrm{p}}^{2}=.002\right)$. There were no two-way interactions of the Trial variable

22 with the independent variables $\left(\right.$ Trial $\times$ Source, $F(1,102)=.140, p=.709, \eta_{\mathrm{p}}{ }^{2}=.001$; Trial $\times$ 
1 Source Expertise, $\left.F(1,102)=1.06, p=.304, \eta_{\mathrm{p}}{ }^{2}=.010\right)$. However, there was a three-way

2 interaction of Trial $\times$ Source $\times$ Source Expertise, $\left(F(1,102)=10.32, p=.002, \eta_{\mathrm{p}}{ }^{2}=.092\right)$.

3 The hypothesized interaction of Trial $\times$ Source $\times$ Source Expertise interaction (see Figure

4 2) reached significance $(p=.002)$, and we further examined Trial 1 and Trial 2 performance

5 scores separately in 2 Source (ingroup, outgroup) $\times 2$ Source Expertise (low, high) ANOVAs.

6 For the Trial 1 performance scores, the analysis revealed a main effect of Source $(F(1,102)=$

$\left.712.85, p=.001, \eta_{\mathrm{p}}{ }^{2}=.112, \mathrm{CI}=[-9.83 ;-2.82]\right)$, indicating that, overall, performance scores were

8 better in the ingroup $(M=41.30, S D=9.20)$ than the outgroup condition $(M=47.63, S D=8.73)$.

9 There was no main effect of Source Expertise $\left(F(1,102)=.809, p=.371, \eta_{\mathrm{p}}{ }^{2}=.008\right)$. However,

10 there was a Source $\times$ Source Expertise interaction $\left(F(1,102)=6.037, p=.016, \eta_{\mathrm{p}}{ }^{2}=.056\right)$.

11 Simple effects analysis of the interaction showed there was a main effect for source expertise

12 only in the ingroup condition, $\left(F(1,55)=5.837, p=.019, \eta_{\mathrm{p}}{ }^{2}=.196, \mathrm{CI}=[-10.84 ;-1.01]\right)$, with

13 better Trial 1 performance in the low $(M=38.33, S D=9.76)$ than in the high $(M=44.25, S D=$

14 8.62) expertise condition. There was no main effect for source expertise in the outgroup

15 condition, $\left(F(1,47)=1.188, p=.281, \eta_{\mathrm{p}}{ }^{2}=.025, \mathrm{CI}=[-2.32 ; 7.82]\right)$, indicating no difference in

16 Trial 1 performance in the low $(M=49.00, S D=7.22)$ and high $(M=46.25, S D=10.24)$

17 expertise conditions.

18 For the Trial 2 performance scores, the analysis revealed a main effect of Source $(F(1$,

$\left.19102)=6.44, p=.013, \eta_{\mathrm{p}}{ }^{2}=.059, \mathrm{CI}=[-13.43 ;-1.64]\right)$, indicating that, overall, performance 2

20 scores were better in the ingroup $(M=17.32, S D=14.98)$ than the outgroup condition $(M=$

$2124.61, S D=15.95)$. There was no main effect of Source Expertise $(F(1,102)=.352, p=.554$,

$\left.22 \eta_{\mathrm{p}}^{2}=.003\right)$. However, there was a Source $\times$ Source Expertise interaction $(F(1,102)=4.194, p=$ $\left.23.043, \eta_{\mathrm{p}}{ }^{2}=.039\right)$. Simple effects analysis of the interaction showed there was a main effect for 
1 source expertise only in the ingroup condition, $\left(F(1,55)=4.112, p=.047, \eta_{\mathrm{p}}{ }^{2}=.070, \mathrm{CI}=\right.$

$2[0.092 ; 15.60])$, with better Trial 2 performance in the high $(M=13.19, S D=10.00)$ than in the

3 low $(M=21.04, S D=17.71)$ expertise condition. There was no main effect for source expertise

4 in the outgroup condition, $\left(F(1,47)=.897, p=.348, \eta_{\mathrm{p}}{ }^{2}=.019, \mathrm{CI}=[-13.50 ; 4.86]\right)$, indicating

5 no difference in Trial 2 performance in the low $(M=22.50, S D=15.41)$ and high $(M=26.82$,

$6 \quad S D=16.53)$ expertise conditions.

\section{$7 \quad$ Success expectations}

There was no main effect of Source, $\left(F(1,102)=.020, p=.887, \eta_{\mathrm{p}}{ }^{2}=.000, \mathrm{CI}=[-8.24\right.$;

9 9.51]), as ingroup $(M=56.26, S D=24.80)$ and outgroup $(M=56.14, S D=22.75)$ success

10 expectations scores were very similar. There was a main effect of Source Expertise, $(F(1,102)=$

$\left.114.983, p=.028, \eta_{\mathrm{p}}{ }^{2}=.047, \mathrm{CI}=[-18.87 ;-1.11]\right)$, indicating that that success expectations scores

12 were higher in the high expertise condition $(M=61.76, S D=22.42)$ compared to the low

13 expertise condition $(M=51.05, S D=24.00)$. As shown in Figure 3, there was also a significant

14 interaction of Source $\times$ Source Expertise, $F(1,102)=4.69, p=.033, \eta_{\mathrm{p}}{ }^{2}=0.044$. Simple effects

15 analysis of the interaction showed there was a main effect for source expertise only in the

16 ingroup condition, $\left(F(1,55)=10.48, p=.002, \eta_{\mathrm{p}}{ }^{2}=.160, \mathrm{CI}=[-31.89 ;-7.50]\right)$, with higher

17 success expectations in the high expertise condition $(M=66.63, S D=21.11)$ than in the low

18 expertise condition $(M=46.93, S D=24.46)$. There was no main effect for source expertise in

19 the outgroup condition, $\left(F(1,47)=.002, p=.965, \eta_{\mathrm{p}}{ }^{2}=.000, \mathrm{CI}=[-13.51 ; 12.92]\right)$, as success

20 expectations in the high expertise $(M=56.29, S D=23.02)$ and low expertise $(M=56.00, S D=$

$2122.96)$ conditions were very similar.

Possible mediation of performance by success expectations. Because there was a main

23 effect of source expertise on performance change scores only in the ingroup condition, we 
1 analyzed the ingroup and outgroup condition data separately using linear regression to test

2 success expectations as a mediator of the effect of expertise on performance change scores. As in

3 the ANOVA results above, in the ingroup, expertise condition was a significant predictor of

4 performance change scores $(\beta=-.403, \mathrm{SE} \beta=.748, t(55)=-3.26, p=.002, \mathrm{CI}=[-3.94 ;-.941])$.

5 When both condition (expertise) and success expectations were entered into a linear regression

6 model predicting performance change scores for the ingroup participants, expertise condition

7 remained a significant predictor of performance change scores $(\beta=-.409, \operatorname{SE} \beta=.824, t(54)=-$

$83.00, p=.004, \mathrm{CI}=[-4.12 ;-.825])$, but success expectations were not a significant predictor $(\beta=$

$9 \quad .015, \mathrm{SE} \beta=.017, t(54)=.109, p=.91, \mathrm{CI}=[-.032 ; .035])$.

10 In the outgroup, expertise condition was not a significant predictor of performance

11 change scores $(\beta=.217, \mathrm{SE} \beta=.814, t(47)=1.52, p=.134, \mathrm{CI}=[-.395 ; 2.88])$. When both

12 condition (expertise) and success expectations were entered into a linear regression model

13 predicting performance change scores for the outgroup participants, expertise condition remained

14 a non-significant predictor of performance change scores $(\beta=.218, \operatorname{SE} \beta=.822, t(46)=1.51, p$

$15=.137, \mathrm{CI}=[-.411 ; 2.89])$, and success expectations were not a significant predictor $(\beta=-.035$,

$16 \operatorname{SE} \beta=.018, t(46)=-.243, p=.80, \mathrm{CI}=[-.041 ; .032])$.

\section{Discussion}

Thus, in Experiment 2, following failure, functional feedback from an ingroup expert

19 resulted in higher success expectations and performance improvement, although it does not

20 appear that success expectations mediated the improvement in performance. It also appears that

21 if the source of the functional feedback is perceived to be from an outgroup, there is no

22 beneficial effect of feedback on subsequent performance, even if the source is someone with

23 high expertise. Interestingly, and consistent with past social identity research, Experiment 2 
1 revealed an overall ingroup "advantage" at Trial 1 that was preserved at Trial 2, with participants

2 in ingroup conditions producing better performance on both trials than participants in the

3 outgroup conditions. However, in Trial 1, the significant Source $\times$ Source Expertise interaction

4 that showed the Expertise main effect only in the ingroup condition also indicated performance

5 was significantly worse in the high than the low expertise condition. By comparison, in Trial 2,

6 the significant Source $\times$ Source Expertise interaction that showed the Expertise main effect only

7 in the ingroup condition indicated performance was significantly better in the high expertise

8 condition. It appears the feedback delivered by the ingroup expert was quite important in

9 overcoming what could be characterized as a "performance deficit" at Trial 1 for this group of

10 students. In other words, in the ingroup condition, there was no high expert advantage at Trial 1

11 that was preserved at Trial 2. In this sense, what is occurring at Time 2 was not present at Time 1

12 and thus the Time 2 effect on performance for the ingroup expert group does not appear to be an

13 artefact of what was present at Time 1.

14 Although Experiment 1 and Experiment 2 differ in some of the detailed results of each

15 study (i.e., the hypothesized three-way interaction clearly present in Experiment 2 but not

16 straightforwardly-significant in Experiment 1; the presence of an ingroup performance advantage

17 in Experiment 2 but not Experiment 1), there is a consistent pattern of the central finding across

18 the two studies - an ingroup source appears to be a prerequisite for expertise to benefit

19 performance through encouraging feedback after failure. Conversely, being an outgroup member

20 appears to inhibit the positive impact of source expertise on performance.

\section{General Discussion}

22 Failure situations can be very challenging for managers, educators, and parents, who

23 often must deliver feedback that is aimed at fostering a renewed desire to persist or improve 
1 despite setbacks. Encouraging feedback following failure that focuses on unstable/controllable

2 ("functional) attributions about the cause of failure has been shown to have positive effects on

3 persistence and performance after failure in academic (Haynes et al., 2010) and sport domains

4 (Coffee, Rees, \& Haslam, 2009). In addition to the attributional features of feedback,

5 communicator ("source") characteristics play a role in feedback effectiveness. Expert sources are

6 generally more influential than non-experts (Petty \& Wegener, 1998; Tobin \& Raymundo,

7 2009), but feedback from outgroup sources is often less effective than feedback from ingroup

8 sources, regardless of the expertise, experience, or credibility of the source (e.g., Greenaway et

9 al., 2015; Morton et al., 2012; Petty \& Wegener, 1998), or even the quality of the arguments

10 (e.g., Esposo, Hornsey, \& Spoor 2013).

11 The present two field experiments sought to address a research gap between the large

12 causal attribution literature about the effectiveness of encouraging (functional) attributional

13 feedback on performance (e.g., Haynes et al., 2010), and the extensive research on social identity

14 variables (ingroup/outgroup; expertise) that influence feedback effectiveness, since it was

15 unknown whether social identity variables moderate the effects of functional attributional

16 feedback on performance, particularly in performance relevant settings (Coffee, 2010; Rees et

17 al., 2013). In the present experiments, after an initial failure, source expertise influenced

18 performance (Experiments 1 and 2) and success expectations (Experiment 2) only in the ingroup

19 condition-performance was significantly better when the encouraging feedback came from an

20 ingroup member presented as an expert in the task rather than from any other source. In addition,

21 in Experiment 1, only those in the ingroup expert condition showed improvement from Trial 1 to

22 Trial 2, with an effect size indicating substantial improvement. In Experiment 2, while

23 performance improved from Trial 1 to Trial 2 in all experimental conditions, those in the ingroup 
1 expert condition again showed the most impressive improvement. These results are promising as

2 they are consistent across two different environments and age groups (i.e., school, university) as

3 well as two different achievement tasks (i.e., motor skill, perception/cognition). In other words,

4 the generalizability of the predicted impact of ingroup expertise across different achievement

5 tasks, environments, and age groups suggests it is independent of these factors. Theoretically,

6 attributional effects should be consistent across tasks within the achievement domain/context

7 (Weiner, 1985). However, one disadvantage of using different tasks from different domains is

8 the risk of finding task-specific effects. Although the present studies are suggestive, further

9 research is needed to examine how generalizable the predicted impact of ingroup expertise is

10 across different achievement tasks, environments, and age groups.

11 The present findings are consistent with previous social identity research that has

12 revealed the communicative challenges of outgroup members, who, despite high expertise, are

13 unable to influence behaviour change the way an ingroup expert does. Being an outgroup

14 member appears to inhibit the impact of source expertise on performance after failure, even

15 when the feedback is encouraging. For outgroup members, then, it is probably necessary to first

16 build and share a common identity (e.g., for a "new" coach or teacher), and then to demonstrate

17 expertise. If already an ingroup member, the focus should be on demonstrating expertise. In

18 addition to the practical advantages of helping coaches, educators, and leaders deliver the kind of

19 feedback that fosters a renewed desire to persist despite setbacks, our results indicate that

20 increasing expertise alone will not necessarily result in desired performance effects. The key is

21 the relationship (a shared common identity), and thus to increase transfer of expertise, our

22 findings suggest a need to focus on helping experts cultivate shared identity with those with

23 whom they work. This might be more important than acquiring more expertise or reconfiguring 
1 how to deliver that expertise. Although the operationalization of Source (known

2 teacher/instructor versus unknown teacher/instructor) in the present studies was considered

3 strong enough for the purposes of the studies, it is not clear "how much" the source was

4 perceived as an ingroup or outgroup member. Future studies will address the extent to which the

5 strength of the perceived source affiliation to the group may moderate the effects of attributional

6 feedback in a performance failure situation.

7 While consistent with previous research, the present findings raise the question of

8 whether a high-status outgroup source (e.g., a well-known, successful coach of a national team)

9 would be ineffectual in improving performance or success expectations. A limitation of the

10 present studies was the definition of expertise simply as being "a specialist" or not in the task.

11 Expertise (high versus low) might better be examined by making differences in expertise more

12 salient through status level (e.g., well-known coach of a national team versus a volunteer coach)

13 or overt behavior (e.g., a highly successful demonstration versus a failed one). It is unknown if

14 functional attributional feedback from an outgroup source recognized as a leading expert in the

15 domain generates comparable, worse, or better performance benefits than an ingroup expert

16 source in the performance relevant setting. The status level of the outgroup source may prove to

17 be another key variable that obviates the communicative challenges faced by outgroup sources

18 delivering attributional feedback after failure.

19 Success expectations were not a mediator of the ingroup expert's effectiveness in

20 improving performance in Experiment 2. Although success expectations and performance

21 improvements were significantly better in the ingroup high expertise condition (compared to the

22 other conditions), we found no evidence that expectations mediated the significant performance

23 improvement linked to the ingroup expert. The lack of mediation by success expectations 
1 suggests another process may be operating to produce both the performance improvement and

2 higher success expectations in the ingroup expert condition. Future research might examine the

3 nature and depth of functional attributional feedback processing in relation to source

4 characteristics (e.g., Maitner, Mackie, Claypool, \& Crisp, 2010), or even the order of

5 presentation of source characteristics and message, since when source identity is revealed

6 following a message (as in the present two experiments), an ingroup source's arguments are

7 processed longer than an outgroup source's arguments (e.g., Mackie et al., 1992).

\section{Conclusion}

9 The present results confirm existing research, and address through field studies a gap

10 between causal attribution findings of performance benefits from encouraging feedback, and

11 social identity research findings showing the importance of source characteristics on feedback

12 effectiveness. In two performance relevant settings, with two different samples (school,

13 university), being an ingroup source appears to be a prerequisite for expertise to benefit

14 performance through encouraging feedback after failure. Conversely, being an outgroup member

15 appears to inhibit the positive impact of source expertise on performance. The present data

16 suggest that a shared identity between coaches, educators, and leaders and those they lead may

17 help convert expert performance advice into real performance benefits. Sharing a common

18 identity may be the foundation upon which expertise leads to gains in performance; thus coaches,

19 educators, and leaders may need to build identity and rapport with athletes and not rely on their

20 reputation (expertise) to exert performance effects.

\section{References}

22 Bakeman, R. (2005). Recommended effect size statistics for repeated measures designs.

23 Behavior Research Methods, 37(3), 379-384. 
1 Chalabaev, A., Sarrazin, P., Fontayne, P., Boiché, J., \& Clément-Guillotin, C. (2013). The influence of sex stereotypes and gender roles on participation and performance in sport and exercise: Review and future directions. Psychology of Sport and Exercise, 14(2), 136-144. doi:10.1016/j.psychsport.2012.10.005

Coffee, P. (2010). Attributions: Contemporary research and future directions. Sport \& Exercise Psychology Review, 6(2), 6-18.

Coffee, P., Rees, T., \& Haslam, S. A. (2009). Bouncing back from failure: The interactive impact of perceived controllability and stability on self-efficacy beliefs and future task performance. Journal of Sports Sciences, 27(11), 1117-1124. doi:10.1080/02640410903030297

Dweck, C. S., \& Leggett, E. L. (1988). A social-cognitive approach to motivation and personality. Psychological Review, 95, 256-273.

Esposo, S. R., Hornsey, M. J., \& Spoor, J. R. (2013). Shooting the messenger: Outsiders critical of your group are rejected regardless of argument quality. British Journal of Social Psychology, 52(2), 386-395. doi:10.1111/bjso.12024

Faul, F., Erdfelder, E., Lang, A.-G., \& Buchner, A. (2007). G*Power 3: A flexible statistical power analysis for the social, behavioral, and biomedical sciences. Behavior Research Methods, 39, 175-191.

Faul, F., Buchner, A., Erdfelder, E., \& Lang, A.-G. (2014). G*Power program version 3.1.9.2. Downloaded from http://www.gpower.hhu.de/

Greenaway, K. H., Wright, R. G., Willingham, J., Reynolds, K. J., \& Haslam, S. A. (2015). Shared identity is key to effective communication. Personality and Social Psychology Bulletin, 41(2) 171-182. 
1 Haynes, T. L., Perry, R. P., Stupnisky, R. H., \& Daniels, L. M. (2010). A Review of attributional retraining treatments: Fostering engagement and persistence in vulnerable college students. In J. C. Smart (Ed.), Higher Education: Handbook of Theory and Research, 24, 227-272. New York: Springer.

Hong, Y. Y., Chiu, C. Y., Dweck, C. S., Lin, D., \& Wan, W. (1999). Implicit theories, attributions, and coping: A meaning system approach. Journal of Personality and Social Psychology, 77, 588-599.

Hornsey, M. J., \& Imani, A. (2004). Criticizing groups from the inside and the outside: An identity perspective on the intergroup sensitivity effect. Personality and Social Psychology Bulletin, 30(3), 365-383. doi:10.1177/0146167203261295

Hornsey, M. J., Oppes, T., \& Svensson, A. (2002). “It's OK if we say it, but you can't:” Responses to intergroup and intragroup criticism. European Journal of Social Psychology, 32, 293-307. doi:10.1002/ejsp.90

Le Foll, D., Rascle, O., \& Higgins, N. C. (2008). Attributional feedback-induced changes in functional and dysfunctional attributions, expectations of success, hopefulness, and shortterm persistence in a novel sport. Psychology of Sport and Exercise, 9, 77-101. doi:10.1016/j.psychsport.2015.01.003

Mackie, D. M., Gastardo-Conaco, M. C., \& Skelley, J. J. (1992). Knowledge of the advocated position and the processing of in-group and out-group persuasive messages. Personality and Social Psychology Bulletin, 18(2), 145-151. doi:10.1177/0146167292182005

Maitner, A. T., Mackie, D. M., Claypool, H. M., \& Crisp, R. J. (2010). Identity salience moderates processing of group-relevant information. Journal of Experimental Social Psychology, 46, 441-444. doi:10.1016/j.jesp.2009.11.010 
1 Marx, D. M., \& Goff, P. A. (2005). Clearing the air: The effect of experimenter race on target's test performance and subjective experience. British Journal of Social Psychology, 44(4), 645-657. doi:10.1348/014466604X17948

Marx, D. M., \& Roman, J. S. (2002). Female role models: Protecting women's math test performance. Personality and Social Psychology Bulletin, 28(9), 1183-1193. doi: $10.1177 / 01461672022812004$

Molden, D. C., \& Dweck, C. S. (2006). Finding “meaning” in psychology: A lay theories approach to self-regulation, social perception, and social development. American Psychologist, 61, 192-203. doi:10.1037/0003-066X.61.3.192

Morton, T., Wright, R., Peters, K. O., Reynolds, K. J., \& Haslam, S. A. (2012). Social identity and the dynamics of organizational communication. In H. Giles (Ed.), Handbook of intergroup communication (pp. 319-330). New York, NY: Routledge.

Mueller, C. M., \& Dweck, C. S. (1998). Praise for intelligence can undermine children's motivation and performance. Journal of Personality and Social Psychology, 75(1), 33-52.

Petty, R. E., \& Wegener, D. T. (1998). Attitude change: Multiple roles for persuasion variables. In D. Gilbert, S. Fiske, \& G. Lindzey (Eds.), The handbook of social psychology (Vol. 1, pp. 323-390). New York: McGraw-Hill.

Rabinovich, A., Morton, T. A., Crook, M., \& Travers, C. (2012). Let another praise you? The effects of source and attributional content on responses to group-directed praise. British Journal of Social Psychology, 51(4), 753-761. doi:10.1111/j.2044-8309.2011.02093.x

Rascle, O., Le Foll, D., Charrier, M., Higgins, N. C., Rees, T., \& Coffee, P. (2015). Durability and generalization of attribution-based feedback following failure: Effects on 
expectations and behavioral persistence. Psychology of Sport \& Exercise, 18, 68-74. http://dx.doi.org/10.1016/j.psychsport.2015.01.003

Rascle, O., Le Foll, D., \& Higgins, N. C. (2008). Attributional retraining alters novice golfers' free practice behavior. Journal of Applied Sport Psychology, 20(2), 157-164. doi:10.1080/10413200701805307

Rees, T., Salvatore, J., Coffee, P., Haslam, S. A., Sargent, A., \& Dobson, T. (2013). Reversing downward performance spirals. Journal of Experimental Social Psychology, 49(3), 400403. doi:10.1016/j.jesp.2012.12.013

Rudolph, U., Roesch, S. C., Greitemeyer, T., \& Weiner, B. (2004). A meta-analytic review of help giving and aggression from an attributional perspective: Contributions to a general theory of motivation. Cognition and Emotion, 18(6), 815-848.

Smith, J. R., \& Hogg, M. A. (2008). Social identity and attitudes. In W. Crano \& R. Prislin (Eds.), Attitudes and attitude change (pp. 337-360). New York: Psychology Press.

Steele, C. M. (1997). A threat in the air: How stereotypes shape intellectual identity and performance. American Psychologist, 52(6), 613-629. doi:10.1037/0003-066X.52.6.613

Steele, C. M., \&Aronson, J. (1995). Stereotype threat and the intellectual test performance of African Americans. Journal of Personality and Social Psychology, 69, 797-811. doi:10.1037/0022-3514.69.5.797

Tajfel, H., \& Turner, J. (1979). An integrative theory of intergroup conflict. In W. Austin \& S. Worchel (Eds.), The social psychology of intergroup relations (pp. 33-48). Pacific Grove, CA: Brooks. 
1 Tajfel, H., \& Turner, J. C. (1986). The social identity theory of inter-group behavior. In S. Worchel \& W. Austin (Eds.), Psychology of intergroup relations (pp. 7-24). Chicago: Nelson-Hall.

4 Tobin, S., \& Raymundo, M. (2009). Persuasion by causal arguments: The motivating role of perceived causal expertise. Social Cognition, 27(1), 105-127.

6 Tormala, Z. L., Briñol, P., \& Petty, R. E. (2006). When credibility attacks: The reverse impact of source credibility on persuasion. Journal of Experimental Social Psychology, 42(5), 684691. doi:10.1016/j.jesp.2005.10.005

9 Weiner, B. (1985). An attributional theory of achievement motivation and emotion. 
2 Figure 1

3 Mean Trial 1 and Trial 2 performance scores (average distance (in $\mathrm{cm}$ ) from the target) in

4 Source (Ingroup/Outgroup) and Source Expertise (Low/High) conditions in Experiment 1. Error

5 bars are standard error.

6

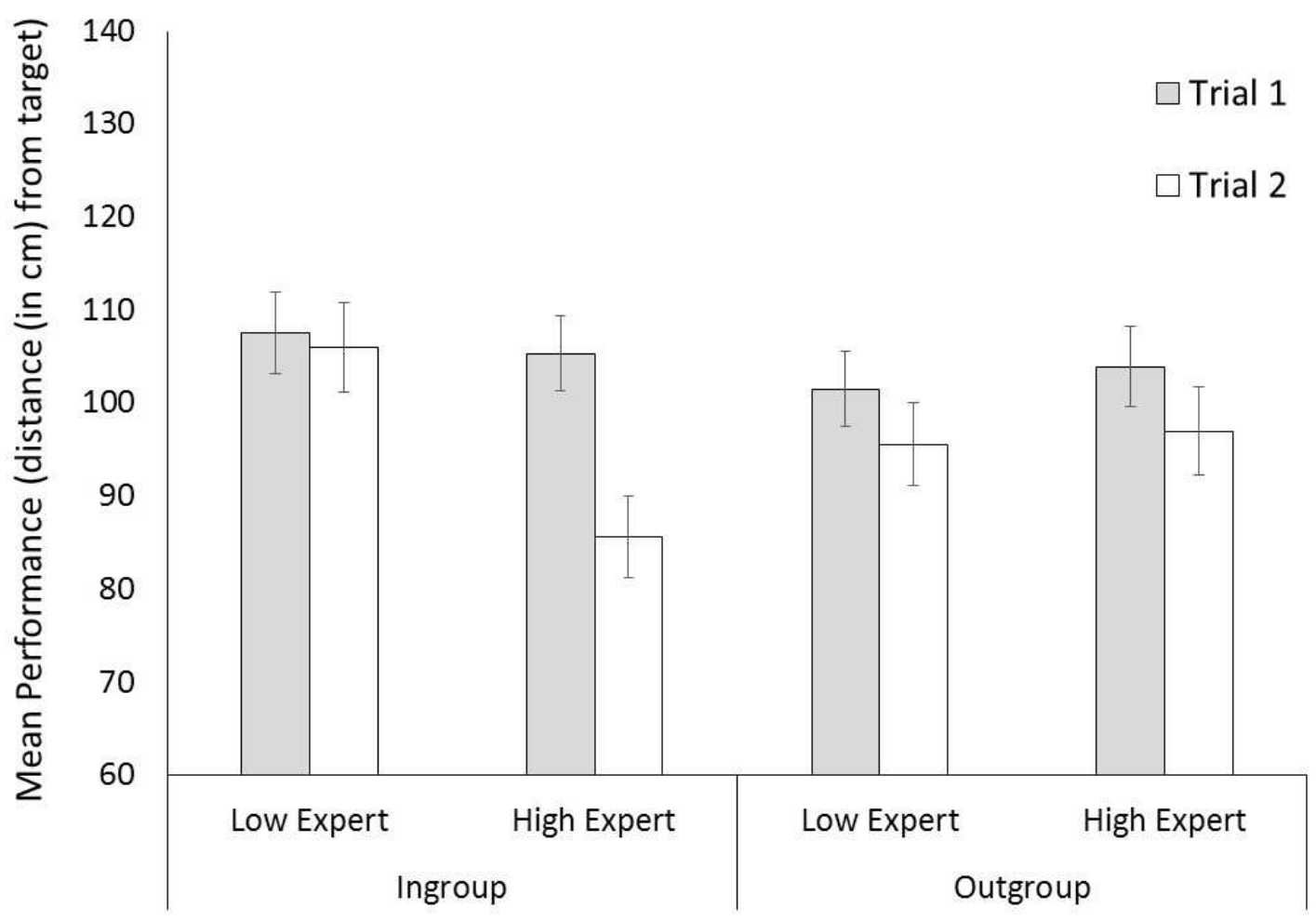

7

8 
$1 \quad$ Figure 2

2 Mean Trial 1 and Trial 2 performance scores (percent error) in Source (Ingroup/Outgroup) and

3 Source Expertise (Low/High) conditions in Experiment 2. Error bars are standard error.

4

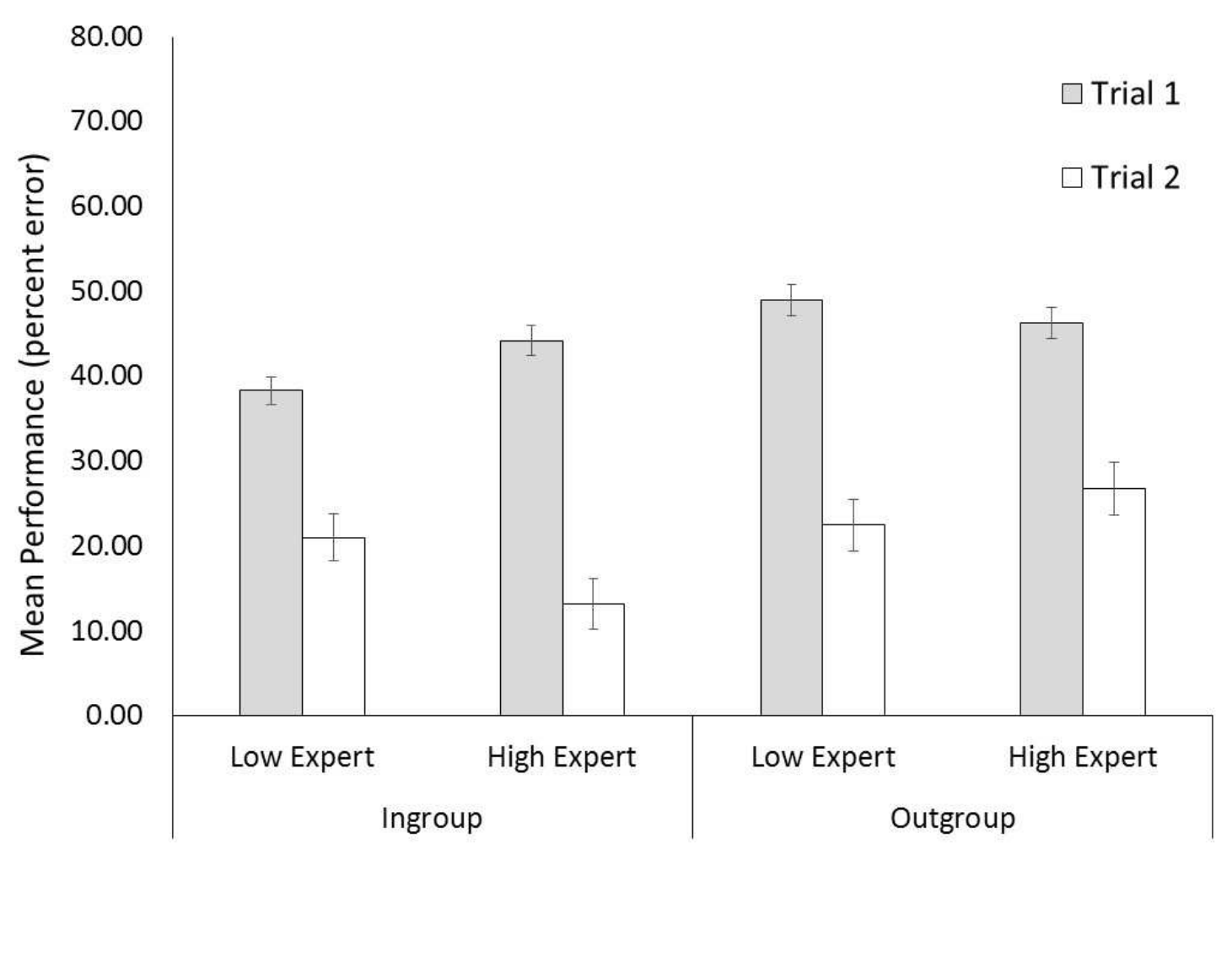


$1 \quad$ Figure 3

2 Mean success expectations score (percent) in Source (Ingroup/Outgroup) and Source Expertise 3 (Low/High) conditions in Experiment 2. Error bars are standard error.

4

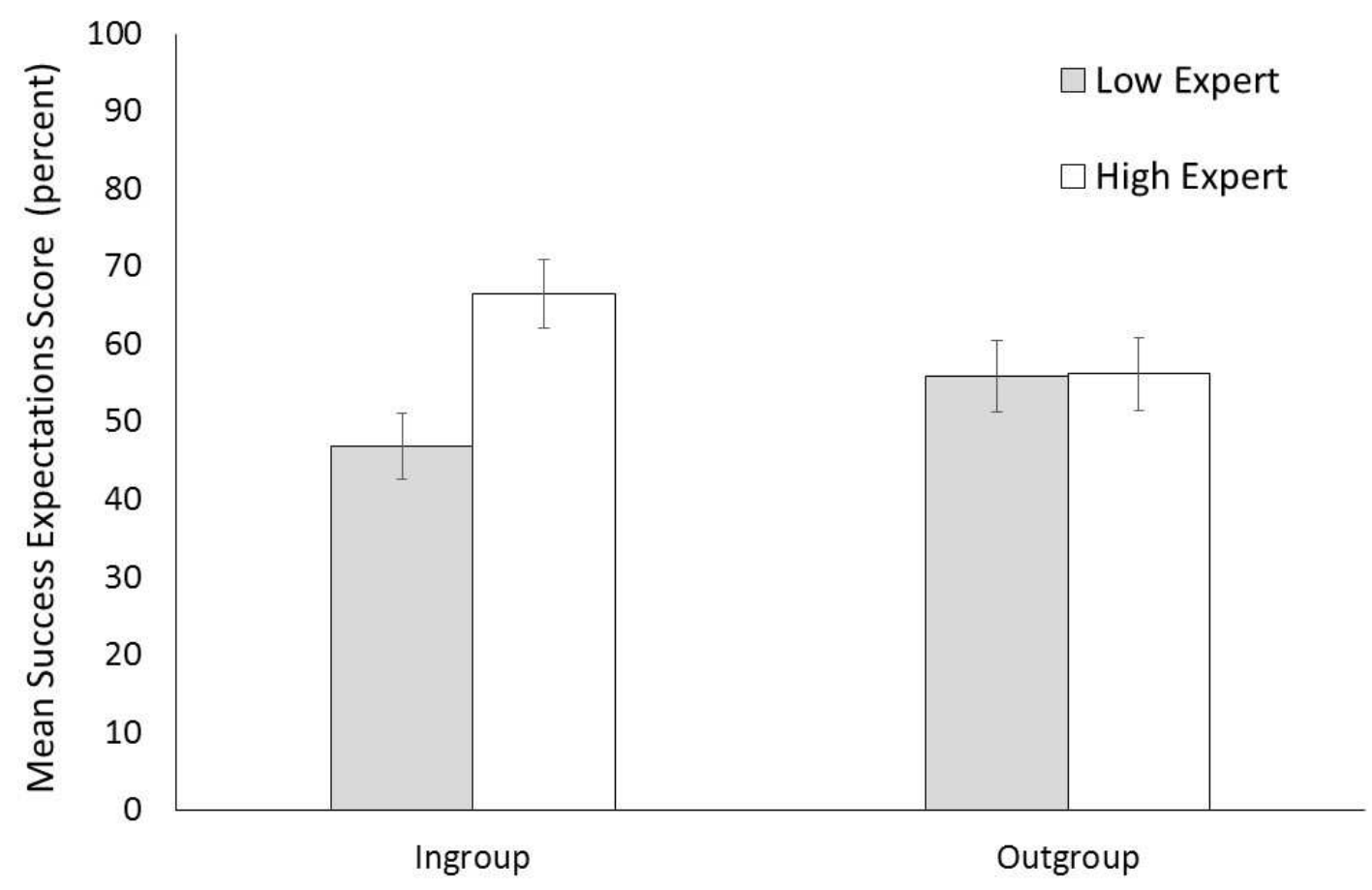

